\title{
Expectation differences between students and staff of us- ing learning analytics in Finnish universities
}

\author{
Jussi Okkonen ${ }^{1}$ Tanja Helle ${ }^{1}$ and Hanna Lindsten ${ }^{1}$ \\ ${ }^{1}$ Tampere University, FIN-33014 Tampere, Finland \\ jussi.okkonenetuni.fi
}

\begin{abstract}
The aim of this paper is to examine and discuss the dissonance between expectations and hopes towards utilising learning analytics in Finnish universities. The analysis is based on data collected among Finnish university students and staff in spring 2019. As a key result we present, that the university staff found it important that all data and information should and could be used for various planning, management and counselling purposes. At the same time student found it unnecessary or even harmful to allow university staff examine their personal data. We therefore propose that universities should develop and implement specific policy for using of analytical data.
\end{abstract}

Keywords: learning analytics, higher education, user expectations, survey

\section{Introduction}

Using learning analytics in higher education is a game of contractionary hopes, motives and goals. In general, the literature draws an idealistic picture of well-functioning apparatus that supports studying process, enhances learning outcomes and eases the managerial burden. The praxis is different as there are several different conceptions of learning analytics and motivations of using it. Also, the personal role in the organisation affects to attitudes.

Extensive use of educational technology, especially digital learning environments, digital curricula, and digital managerial systems have brought about the need for analytics to monitor the use of the learning environments and the learning itself. Technology that is more sophisticated is provided by educational technology industry to better serve teachers, end users and primary customers. There are four main trends in enhancing teaching and learning practices. On micro level (learning event), analytics is for assessment of achieving certain goals. On meso level (subject level), i.e. implementing the curricula analytics are for achievements, adaptivity and general assessment. On macro level analytics if for promoting management by knowledge, risk assessment and measuring key performance indicators on different levels. The fourth trend is compliance, privacy, and security issues on the level mentioned and can be considered as the primary prerequisite for utilising learning analytics.

The levels of learning analytics could be elaborated as follows:

- Micro level concentrates on student and individual learning processes. This is enabled by gathering extensive, high quality data on student transactions and subject under study. 
- Meso level concentrates on tuition provider and development of teaching practices. This level includes the levels of subject, curricula and teaching events as aggregate.

- Macro level learning analytics aims to managing learning by knowledge, recognition of risks and acknowledging hindrances of optimal flow in learning processes.

On all three levels learning analytics are somewhat overlapping and complementary.

Learning analytics aims to visualise, analyse, and interpret the actions of users in the context of learning and teaching (e.g. [1],[2],[3]). By achieving these aims new ways of teaching, learning, organisational functioning, and decision making could be achieved. To fully utilise learning analytics also ethical and privacy issues must be concerned [4], [5]. The gathering and integration of the data, providing consent, anonymisation of data, transparency, information security, interpretation of the data, data management are issues of national and international laws and statutes that should be taken into account when learning analytics is integrated into educational technology. In order to reach beyond the state of the art learning analytics needs to be developed in cooperation with key stakeholders, e.g. students, institutions and teachers [6]. Moreover, practices should be developed, tested, and validated in wild among practitioners. The development should be conducted in dialogue on the levels of technology, studying and teaching, and administrative practices.

In recent studies ethical issues have been considered. In particular, there have been concerns about misusing the data by individuals and that decisions are made based on incorrect information or that learning analytics itself is based on false techniques. However, in a study implemented in 2017, it was found that students are rarely asked what they think about using learning analytics [4]. This deficiency itself can be seen as an ethical issue which was strongly raised in the result of our study. It is important to note, that approximately $40 \%$ on responded students answered, that there are some ethical issues to consider.

Ethical issues are studied in the study of Kimberly, Arnold and Slater [4]. They explored student perceptions of their privacy in learning analytics applications. The study showed that the majority of the students accepted the use of their data but also approval varies depending on suggested aim of the analytics. The variations between students enrolled at British and American educational institutions were recognized as well. In that study more than half of American respondents and only a quarter of the respondents from United Kingdom would like to have a possibility to compare with other students in the learning analytics application. The researchers explained that students were unclear of exactly how the comparison would happen, for instance how anonymously it would have implemented. Addition to ethical issues, students' expectations were also taken account into Whitelock-Wainwright et al. [7] who present a descriptive tool for measuring student expectations of learning analytics services. Expectations can be distinguished between ideal and predicted expectations. Through literature the researchers produced four identified expectation themes: ethical and privacy, agency, intervention, and meaningfulness expectations [7].

Using learning analytics in higher education is a game of contractionary hopes, motives and goals. In general, the literature draws an idealistic picture of well-functioning 
apparatus that supports studying process, enhances learning outcomes and eases the managerial burden. The praxis is different as there are several different conceptions of learning analytics and motivations of using it. Also, the personal role in the organisation affects to attitudes. The aim of this paper is to examine and discuss the dissonance between expectations and hopes towards utilising learning analytics in Finnish universities. The analysis is based on data collected among Finnish university students and staff in spring 2019.

\section{Data on Finnish students and university staff}

The data of this study has been collected from six Finnish universities during the spring of 2019. The universities are Tampere University, Aalto University, LUT University, University of Turku, University of Eastern Finland and University of Oulu. The inquiry was disseminated through news bulletins of university intranet sites and targeted mailing lists. The purpose was to reach the widest possible range of respondents. The respondents were divided according to the user groups of the analytical data, into groups of students, teachers, teacher tutors, i.e. those who are responsible for the academic counselling of individuals, study coordinators and those responsible for education. Each of these groups had their own form to answer, questions targeted to take in to account their possible, special needs on utilizing learning analytics. Heads of study affairs, heads of degree programmes, deans and vice deans responsible for education were instructed to respond to the survey of those responsible for education. In one of the six universities (University of Oulu), the inquiry was only distributed to a teacher tutor. The way in which a poll was distributed in each university varied, so that it is very difficult to estimate the number of respondents to the inquiry and thus the response rate. It is known that there are a total of 77430 Bachelor's or Master's degree students in the six universities. We assume that the different ways in which universities distributed the questionnaire has also had a strong impact on the number of respondents. In the analysis and interpretation of the material, it should be noted that the respondents have had experience with the registry systems used at their own university and in their responses they reflect the experience of that particular system.

Table 1 displays the amount of all students of universities as well as the amounts and percentages of different groups participated in this survey.

Table 1. Respondents of the inquiry

\begin{tabular}{lllllll}
\hline University & $\begin{array}{l}\text { Amount of stu- } \\
\text { dents }\end{array}$ & $\begin{array}{l}\text { Student } \\
\text { re- } \\
\text { sponded }\end{array}$ & $\begin{array}{l}\text { Teachers } \\
\text { re- } \\
\text { sponded }\end{array}$ & $\begin{array}{l}\text { Teacher } \\
\text { tutors re- } \\
\text { sponded }\end{array}$ & $\begin{array}{l}\text { Study } \\
\text { coordi- } \\
\text { nators } \\
\text { re- } \\
\text { sponded }\end{array}$ & $\begin{array}{l}\text { Respon- } \\
\text { sible for } \\
\text { educa- } \\
\text { tion re- } \\
\text { sponded }\end{array}$ \\
\hline $\begin{array}{l}\text { Tampere Univer- } \\
\text { sity }\end{array}$ & 18402 & 150 & 41 & 11 & 21 & 12 \\
& & $66 \%$ & $44 \%$ & $13 \%$ & & $40 \%$
\end{tabular}




\begin{tabular}{|c|c|c|c|c|c|c|}
\hline \multirow{3}{*}{ Aalto University } & \multirow{3}{*}{14712} & & & \multicolumn{3}{|c|}{$44 \%$} \\
\hline & & 50 & 14 & 7 & 2 & 1 \\
\hline & & $22 \%$ & $15 \%$ & $8 \%$ & $4 \%$ & $3 \%$ \\
\hline \multirow[t]{2}{*}{ LUT University } & 4767 & 6 & 6 & - & 3 & 10 \\
\hline & & $3 \%$ & $7 \%$ & & $6 \%$ & $33 \%$ \\
\hline \multirow{2}{*}{$\begin{array}{l}\text { University of } \\
\text { Turku }\end{array}$} & 14178 & 8 & 17 & 7 & 15 & 5 \\
\hline & & $4 \%$ & $18 \%$ & $8 \%$ & $31 \%$ & $17 \%$ \\
\hline \multirow{2}{*}{$\begin{array}{l}\text { University of } \\
\text { Eastern Finland }\end{array}$} & 13884 & 13 & 15 & 7 & 7 & 2 \\
\hline & & $6 \%$ & $16 \%$ & $8 \%$ & $15 \%$ & $7 \%$ \\
\hline \multirow{2}{*}{$\begin{array}{l}\text { University of } \\
\text { Oulu }\end{array}$} & 11487 & - & - & 45 & - & - \\
\hline & & & & $52 \%$ & & \\
\hline $\begin{array}{l}\text { Total number of } \\
\text { respondents of } \\
\text { each group }\end{array}$ & & 227 & 93 & 77 & 48 & 30 \\
\hline
\end{tabular}

The purpose of the five user surveys was primarily to find out what the different user groups consider to be important goals in utilizing analytical information. The survey was not collected primarily for research purpose, it was mainly to be used in the development of applications and information systems utilizing analytical information. This places limitations on the analysis of the material, for example the questions asked to different user groups are not always comparable.

The questionnaires consisted of both multiple choice and open-ended answer questions. Multiple choice answers were directly coded into SPSS which was used for statistical analysis. Open-ended answers were processed by outlining the key topics and 
creating a variety of categories which would describe responses as closely as possible. It is also important to notice that a certain response could include in severe codes.

In the questionnaires there were also open-ended questions in order to help us collect a lot of information about the reasons for different answers. Open-ended answers collected rich information especially in ethical considerations and utilization of the analytical data. Those two questions were presented in all the forms in order to make the comparison possible. In addition, there were also some questions which appeared on some forms. There were 86 responses from the students for question which explored the ethical issues and 81 responses for a question related to how the university should utilize student data. That indicates that more than a third of student respondents answered to these two pure open-ended questions.

The surveys were based on three group interviews for teachers, students, and for study managers and study coordinators together. Based on these background interviews we found that coordinators and study managers have a very different perspective on the use of register and the information based on that. Therefore, separate forms were prepared for them. It was also found that teachers who work as teacher tutors should also have a form their own.

At the same time, it was found that the work of coordinators and teacher tutors, the guidance of studies, often lies at the interface between micro and meso levels, the coordination of teaching and study requirements and the student's personal curriculum. It can be said that the levels of utilization of analytical data are not so much divisible by the actors, but rather the processes that can be supported by analytical data. The levels and processes concerning the analytical information are presented in Table 2.

Table 2. Different agents' processes concerning the analytical information and levels

\begin{tabular}{lll}
\hline Agent & $\begin{array}{l}\text { Process, concerning the analytical } \\
\text { information }\end{array}$ & Level \\
\hline Student & Studying and planning studies & Micro \\
$\begin{array}{l}\text { Coordinator } \\
\text { / Coutor } \\
\text { teacher }\end{array}$ & & Micro \\
Teacher & Planning education &
\end{tabular}

These findings, based on three group interviews as mentioned above, were taken into account in the preparation of the questionnaires. The student's form focused on particular on ways of utilizing analytical knowledge that could support the student's planning, guidance and follow-up. The study coordinator and teacher tutor surveys focused in 
particular on the needs of study guidance and in the teachers' questionnaire on the information to be used in planning teaching of individual courses. In particular, the survey for those who are responsible for the studies focused on information management issues. To collect unpredictable information the question how the university should use the information collected in the systems was asked in all forms.

Ethical issues, especially with regard to the private information about the individual student, were strongly raised in the students' interview. As a result, surveys attempted to identify students' readiness to allow different user groups to utilize student personal information as well as the need for other user groups to utilize such an information. In addition, an open-ended question asked the respondents about the possible ethical problems associated with the use of analytical information.

In this study we found ethical concerns which are partly complementary with those presented, and may be divided into the following three categories: 1) in individual behavior, 2) in policy of institution using learning analytics or 3) in validity and reliability of the data. The ethical considerations are reflected by the results of the study as those the key for justifying the use of learning analytics, successfully implement learning analytic, and executing learning analytic policy of the respective institution.

\section{$3 \quad$ Findings related to expectation differences}

The respondents were either staff members or students that are high achievers in sense of how their studies have progressed. At this point, we were interested in whether the staff and students shared their expectations on learning information system. The expectations about access to students' data and combining that data were studied in Likert type questions. The perceptions of utilisng the learning information system was found out by open-ended questions. The results on these issues were unanimous, based on the view of the majority.

There were several different insights on how data and information from different systems should be used for analytical purposes or even for counselling purposes. The general expectations for information systems were dichotomic. The staff found it almost self-evident that all data and information should and could be used for various planning, management and counselling purposes, yet the students were more critical. Especially use of personal data without permission on consent was the divider. The students had clear idea that the use of any personal data should be authorized by informed consent and the use should also be justified and bound to certain use context. According to the staff, combining the data from different sources would be useful. However, the students didn't appreciate that feature of data usage. Although there were different insights, both staff and students had common sense that analytical data should be used for management and development of studies. Staff's and students' expectations are described in Table 3. 
Table 3. Staff and students' expectations of learning information system

\begin{tabular}{ll}
\hline Staff's expectation & Students' expectation \\
\hline Access to students' data & $\begin{array}{l}\text { Critical attitude, permission on consent required } \\
\text { for personal data } \\
\text { Not combining the data from difference sources } \\
\text { Combine the data from } \\
\text { different sources }\end{array}$ \\
$\begin{array}{l}\text { Data utilized for man- } \\
\text { agement and develop- } \\
\text { ment of studies }\end{array}$ & $\begin{array}{l}\text { Data utilized for management and development of } \\
\text { studies }\end{array}$
\end{tabular}

Teachers having role as a tutor and studying coordinators had explicit wish to have detailed and up to date information on students' personal studying plans, current degree programs and progress of the studies. Staff members also had need for easier access to data and information from different sources. Those in the role of administration had distinctly versatile information need from the systems. Evidently their role requires statistics of attendance, success, and other course or degree related issues. However, coordinators are somewhere in between as they had need for information on individuals as well as on different groups. The staff had needs to drill into student groups, and sometimes even to individuals, in order to maintain view on operational status. There was unanimity that information from different sources could and should be utilised to management and development of studies. However, the extent of using the data and scope varied distinctly among the respondents. Staff's specified expectations are presented in Table 4.

Table 4. Staff's specified expectation of learning information system

\begin{tabular}{ll}
\hline Role of staff & Expectation \\
\hline Tutor teacher & Students' personal studying plan \\
Studying coordinator & Current degree program details \\
Responsible for educa- & Progress of studies \\
tion & Statistics of attendance and success \\
Teacher & Course or degree related issues
\end{tabular}

There are differences among the students between the disciplines and some trend on those discrepancies could be drawn on Table 5. There was somewhat uniform opinion that the system should send notifications to student if progress does not meet the studying plan or if one should enroll to an exam or a course. There was also strong agreement on that system should provide schedule according to planned studies. Those studying in Medical school students were more willing to have ready, general schedule as they have less options in their studies.

Students did not want to be compared with other students, yet there was variation according to the field of studies. The students of humanities were most strictly against comparing individuals yet those studying medical had less objection. Moreover, the 
students of technology had wish for difference performance indicators. The students of medicine and education were most critical toward extensive use of performance indicators. However, there was unanimity on using feedback on good performance to motivate even beyond. The science students seemed to need less this kind of feedback. The students of social sciences were the most unsure on additional features of information systems as they had insight that those should contain curriculum, studying plans and registry for passed courses.

Table 5. Shared and different expectations of the students

\begin{tabular}{ll}
\hline Students' shared expectations (\%) & Students' different expectations (\%) \\
\hline Notification to enroll to an exam or a & Compared with other students \\
course (app. 87\%) & Humanities (85\%) \\
& Medical (57\%) \\
& Use of performance indicators \\
Ready structured schedule related to stud- & Technology (72\%) \\
ying plan (74 \%) & Medical (50\%) \\
& Education (47\%)
\end{tabular}

the studying plan (app. $40 \%$ )

There were some distinctions when comparing according to the year of the studies. Students starting their studies and fourth year students had wish for ready structured schedule. The student between had wish for a ready, yet personalised schedule. This reflects the notion of progress and general performance. Less than half of all students evenly in all programs had wish for notification of underperformance and lagging, but on the other hand also half of them were against such notifications. This seems to divide students, as there were only a few indifferent. Most important system feature was notifications on enrolling certain course or enrolling to exam.

Using information to compare individual performance to peers was mostly welcome by fifth year students, i.e., those about to graduate. Those already behind the designated schedule were mostly against such comparison, obviously for being unwilling to be stigmatized or notified for underperformance. However, there was ambivalence towards performance indicators as first year and fifth year student were in favor of them, but fourth year students were most against. The same groups also wished for motivational feedback for good performance and the analogically the same groups found it unnecessary.

In general, the information system should be beyond of being just repository for passed courses and studying plans. Especially the first, fourth, and sixth year students recognized the need for additional features. However, the respondents were divided as almost one third had no opinion on most additional features.

The ethical considerations varied between different respondent groups. The most distinct difference was between the way the domain and scope of learning analytics activities are justified and accepted. The managerial perspective, i.e. all other respondents than students, see learning analytics as a meso-level and macro-level activity that 
mostly deals with anonymized data and information. The students have totally different notion as they see themselves as subjects of learning analytics activities and they take it quite personally. From the ethics perspective this kind on distinction was established by the authorization about the use of individual data. Students are on micro-level and for them learning is personal and related to achieving their degree. Staff is somewhat liberal on granting or gaining access to student data, even non-aggregated data. The students on the other hand are only willing to grant access only based on justified reasons, e.g. certain staff member is their tutor, or they need some kind of special service provided by the administration. Taking the evident differences between rationale of using learning analytics as well as different scopes and domains of using it, the differences on expectations raise from the presented levels of learning analytics and the sources of ethical issues.

Table 6 indicates the major ethical considerations of different groups. The results show that the policy of institution is seen here as the major ethical consideration. Yet the more accurate reasons behind the policy of institution reveal the different views of the users. The students would like to have strict instructions and transparency of the data while studying coordinators see the data combining as an ethical risk. Those who are responsible for education suggest that only statistical data should be used. In this context the policy of institution means the process related to learning analytics. In the open-ended responses, both the students and staff underlined the concern about how the data is used and they don't necessarily even know how it is used. The majority of teachers pointed out that they don't see any ethical considerations using data. Tutor teachers considered the validity and reliability of the data as the major ethical problem. They were especially worried about the use of sensitive and personal data of students. 
Table 6. Ethical considerations

\begin{tabular}{ll}
\hline The role of respondent & The major ethical consideration (\%) \\
\hline Student & Policy: Strict instructions and transparency (31\%) \\
Teacher & Individual: No ethical considerations (24\%) \\
Tutor teacher & Validity and reliability: Use of sensitive and per- \\
& sonal data (39\%) \\
Studying coordinator & Policy: Combining the data (55\%) \\
Responsible for education & Policy: Only statistical data should be used (27\%)
\end{tabular}

\section{Discussion}

The results presented above implicate that the ethical issues raise from using learning analytics as vehicle and support for tutoring as students and staff members have distinct expectations of how data is gathered, analysed, used and distributed within course, degree program or institution (cf. [9, 10, 11]). The privacy issues are considered as students are reluctant on indifferent to grant access to their personal information for random staff members. On the contrary the managerial perspective for learning analytics calls for accessible data for certain processes or even to ad hoc purposes. This is analogical to all other data privacy discussion as vendors and service providers justify their expanding data consumption by better and well targeted services and products. People, especially those with some degree of privacy awareness, tend to think just the opposite. Especially when analytics is implemented in full extension, the privacy issue, or how my data is used, takes new form. As presented above only half of the students were willing to receive benchmarking or other algorithm powered data on their performance. This reflects to finding that university students considered themselves as part of academic community, not raw material, or livestock, refined for the needs of the society.

Institutions have established policies for using learning analytics and staff mostly comply with those. It is not that divergent expectations exist, but mostly it is about what to staff, and especially teaching staff, is willing to allocate their scarce resources. The survey brought about the issue that teaching staff has low expectations towards learning analytics as they need mostly up to date contacts to students and related information. The realistic expectations of teaching staff seem to dilute the high hopes of data driven tutoring and counselling of students.

Since most of the studying related processes are digitalised and large amount of activities can be carried out in platforms universities provide, the window of opportunities is open for utilising learning analytic, say data driven management, more throughly. The results point out the dichotomy in expectations as students and teachers seek to manage daily activities on micro-level, but those in managerial position seek extensive leverage effect on meso- and macro-levels. These are not contradictory, yet they might not be served by the same development schemes and policies. The students and teachers are willing to maintain personal relationships and utilise digital tools for process man- 
agement. The managerial perspective [over] emphasises openness of the data, analytical approach, and seeking gains on mass as well as putting effort on what brings reward to the institution.

It should be noted that the Finnish university system has so far used very little analytical information in students guidance. As previous research has shown, students tend to be more positive about a system that they already use and whose logic they are familiar with, cf. [7] . Some of the critical attitude of the respondents to the information produced by the hypothetical system may be explained by its unfamiliarity.

\section{Conclusions}

The study was based on simple sample data and therefore the results are explorative by the nature. When assessing the results one should take into account that the original aim was not to conduct an exhaustive survey, but verify the findings of a qualitative user needs study. The results also serve as verification for certain assumptions regarding to attitudes and insight in form of expectations. The results are context sensitive as Finnish higher education has its unique features, yet applicable to those contexts where university education is publicly produced private commodity, i.e. not driven by supply and demand but public steering and financing. Also, important note in contextualising the results is to note that such a system operates in a very different logic than one based on large tuition fees and offering tuition to all with sufficient means to acquire university education.

As stated earlier, the universities have had different ways of inviting to participate in this research. This has affected not only the number of respondents but also the quality of them. Based on the number of credits reported by students, it is noted that $70 \%$ of respondents complete their studies within the target time, while we know that only $20 \%$ of Finnish university students complete their degree in target time. Thus, the sample does not represent the population in this respect.

The future research on the theme will provide additional evidence on user centric approach to learning analytics. The results of this survey are operationalised to design targets and functionalities of a student service as well as how the data could be utilised on micro-, meso- and macro-level in the respective institutions. The main result is, that different groups of users have different aims and needs in using analytical data. The needs of the different groups vary and might even be conflicting. Therefore, it is important to evaluate how the objective of different users of analytical information can be combined. University policy should pay a special attention to the ethical aspects of data use and gaps that may allow individual and sensitive information to fall into the wrong hands. In each situation a student should have an opportunity to decide where his / her personal information will be used and who it is to be seen. 


\section{References}

1. Ferguson, R., Brasher, A., Clow, D., Cooper, A., Hillaire, G., Mittelmeier, J., et al. (2016) Research evidence on the use of learning Analytics: Implications for education policy. European Union, Centre for Research in Education and Educational Technology.

2. Greller, W. and Drachsler, H. (2012) Translating Learning into Numbers: A Generic Framework for Learning Analytics Journal of Educational Technology \& Society Vol. 15, No. 3, Learning and Knowledge Analytics (July 2012), pp. 42-57.

3. Viberg, O., Hatakka, M., Bälter, O. Mavroudi, A. (2018) The current landscape of learning analytics in higher education, Computers in Human Behavior, Volume 89, pp. 98-110.

4. Tsai, Y.-S., Gaševic, D., Whitelock-Wainwright, A., Munoz-Merino, P. J., Moreno-Marcos, P. M., Fernández, A. R., Kollom, K. (2018). SHEILA: Supporting higher education to integrate learning analytics.

5. Kimberly E. Arnold \& Niall Sclater. (2017) Student perceptions of their privacy in learning analytics applications. LAK' 17.

6. Ferguson, R. (2012). Learning analytics: drivers, developments and challenges. International Journal of Technology Enhanced Learning, 4(5/6) pp. 304-317.

7. Whitelock-Wainwright, A, Gašević, D, Tejeiro, R, Tsai, Y-S, Bennett, K. (2019) The Student Expectations of Learning Analytics Questionnaire. Journal of Computer Assisted Learning 35: pp. 633-666.

8. Elouazizi, N. (2014). Critical Factors in Data Governance for Learning Analytics. Journal of Learning Analytics, 1(3), pp. 211-222.

9. Howell, J.A., Roberts, L.D., Seaman, K., Gibson D.C (2018) Are We on Our Way to Becoming a "Helicopter University"? Academics' Views on Learning Analytics Tech Know Learn (23:1).

10. Roberts, L. D., Howell, J. A., Seaman, K., \& Gibson, D. C. (2016b). Student Attitudes toward Learning Analytics in Higher Education: "The Fitbit Version of the Learning World". Frontiers in psychology, 7, 1959.

11. Roberts, L., Chang, V., \& Gibson, D. (2016a). Ethical considerations in adopting a university- and system-wide approach to data and learning analytics. In B. Kei Daniel (Ed.), Big data and learning analytics in higher education (pp. 89-108). Switzerland: Springer. 